\title{
Asteraceae no município de Jacobina, Chapada Diamantina, Estado da Bahia, Brasil
}

\author{
Lúcia Moura ${ }^{1,3}$ e Nádia Roque ${ }^{2}$
}

Recebido: 5.02.2014; aceito: 22.05.2014

\begin{abstract}
Asteraceae in the municipality of Jacobina, Chapada Diamantina, Bahia State, Brazil). Asteraceae is the largest family among Eudicots, with about 24,000 species distributed throughout the world. Jacobina is located at the northern end of Chapada Diamantina and is composed by two main mountains: Serra do Tombador in the western portion, and Serra de Jacobina in the eastern portion. The study aims to survey the flora of Asteraceae of the municipality of Jacobina, discuss occurrence and distribution, and provide a key for species. Samples were collected during five field trips (2011-2012) to different vegetation types and analysis of seven Brazilian herbaria collections. The family is represented by 15 tribes, 61 genera, 80 species, and one hybrid. The most representative tribes were Vernonieae (21 spp.), Eupatorieae (19), and Heliantheae (13), with emphasis on the genera Lepidaploa and Mikania (5 species each). Among the studied taxa, ten have Jacobina as type locality. Lepidaploa muricata is a new record for the Bahia State.
\end{abstract}

Keywords: Compositae, Espinhaço Range, Floristic, Piemonte da Diamantina

RESUMO - (Asteraceae no município de Jacobina, Chapada Diamantina, Estado da Bahia, Brasil). Asteraceae é a maior família dentre as Eudicotiledôneas com cerca de 24.000 espécies distribuídas em todo planeta. Jacobina situa-se no extremo norte da Chapada Diamantina, com duas principais formações montanhosas, a Serra do Tombador na porção oeste e a Serra de Jacobina na porção leste. O estudo tem como objetivo realizar o levantamento florístico de Asteraceae do município de Jacobina, discutir a ocorrência, a distribuição e apresentar uma chave de identificação para as espécies. Foram realizadas cinco viagens de coleta (2011-2012) em diversas fitofisionomias do município e análise das coleções de sete herbários brasileiros. Asteraceae está representada em Jacobina por 15 tribos, 61 gêneros, 80 espécies e um híbrido. As tribos mais representativas foram Vernonieae (21 spp.), Eupatorieae (19) e Heliantheae (13), destacando os gêneros Lepidaploa e Mikania (com 5 espécies cada). Dentre os táxons encontrados, dez têm Jacobina como localidade-tipo e Lepidaploa muricata é uma nova ocorrência para o Estado.

Palavras-chave: Cadeia do Espinhaço, Compositae, Florística, Piemonte da Diamantina

\section{Introdução}

Asteraceae (ou Compositae) é a maior família dentre as Angiospermas, com aproximadamente 24.000 espécies, agrupadas em mais de 1.600 gêneros, o que representa cerca de $10 \%$ de toda a flora mundial (Funk et al. 2009). Apresenta distribuição cosmopolita, sendo mais bem representada nas regiões temperadas e semi-áridas dos trópicos e subtrópicos, em vegetação aberta (áreas de campo e savanas) e de altitude, sendo menos comum em florestas tropicais úmidas de baixa altitude (Anderberg et al. 2007).
A família é caracterizada pelas flores arranjadas em capítulo, androceu sinântero com apresentação secundária do grão de pólen, ovário ínfero bicarpelar, que se desenvolve em uma cipsela geralmente com pápus (Roque \& Bautista 2008, Funk et al. 2009). Não há dúvidas quanto ao monofiletismo de Asteraceae, entretanto estudos moleculares recentes (Panero \& Funk 2008, Funk et al. 2009) propuseram novos arranjos em sua classificação, reconhecendo atualmente 12 subfamílias e 43 tribos.

No Brasil, a família está representada por 278 gêneros e 2.034 espécies, que ocorrem em todos os

1. Universidade Estadual de Feira de Santana, Programa de Pós-Graduação em Botânica, Departamento de Ciências Biológicas, Km 03, BR 116, 44031-460 Feira de Santana, Bahia, Brasil

2. Universidade Federal da Bahia, Instituto de Biologia, Campus Universitário de Ondina, 40170-110 Salvador, Bahia, Brasil

3. Autor para correspondência: lucia.moura@live.com 
biomas, porém com maior riqueza nas formações campestres, principalmente no domínio do Cerrado (Nakajima et al. 2014). Asteraceae apresenta maiores taxas de endemismos nos campos rupestres da Cadeia do Espinhaço, nos Estados de Minas Gerais (Giulietti et al. 1987, Roque 2001, Roque \& Nakajima 2001, Hind 2003, Roque 2005, Almeida 2008, Quaresma et al. 2013, entre outros) e da Bahia (Hind 1995, Zappi et al. 2003, Roque \& Bautista 2007, Funk \& Roque 2011, Roque \& Santana, no prelo).

A Cadeia do Espinhaço é um conjunto de serras que se estende por cerca de mil quilômetros na direção norte-sul, com limite norte na Serra da Jacobina, no Estado da Bahia, e atingindo ao sul a Serra de Ouro Branco, no Estado de Minas Gerais (Giulietti \& Pirani 1988). A Cadeia é formada por uma porção mineira e uma baiana, esta última denominada Chapada Diamantina, na qual estão inclusas a Serra do Tombador e a Serra da Jacobina, que cortam o município de Jacobina (Giulietti \& Pirani 1988, Pinheiro 2004).

Um importante critério utilizado para seleção de áreas prioritárias para conservação é o grau de endemismo da região (Gentry 1986). Áreas montanhosas são reconhecidas como áreas de alto endemismo, portanto, merecem atenção especial na preservação da biodiversidade (Kruckeberger \& Rabinowitz 1985, Hind 1995, Rapini et al. 2002). Dessa forma, inventários florísticos apresentam grande relevância por fornecer informações essenciais para o reconhecimento de tais áreas.

Com isso, o presente trabalho tem como objetivo realizar o levantamento florístico de Asteraceae para o município de Jacobina, Chapada Diamantina, Estado da Bahia, bem como apresentar uma chave de identificação, e discutir a ocorrência e distribuição geográfica das espécies na região.

\section{Material e métodos}

O município de Jacobina faz parte da microrregião do Piemonte da Chapada Diamantina, possui como coordenada central $11^{\circ} 10^{\prime} 50^{\prime \prime} \mathrm{S}$ e $40^{\circ} 31^{\prime} 06^{\prime \prime} \mathrm{W}$, área total de 2.360 quilômetros quadrados e altitudes entre 360 a 1.192 m (Pinheiro 2004, SEI 2014).

O clima de Jacobina varia entre seco sub-úmido e semi-árido, é quente e caracterizado por duas estações definidas (inverno e verão). Possui precipitação média anual em torno de $863 \mathrm{~mm}$, com chuvas concentradas nos meses de janeiro a março (Pinheiro 2004).

A vegetação do município é caracterizada por um mosaico composto por florestas estacionais decíduas e decíduas, campo rupestre, caatinga arbórea e arbustiva, refúgios ecológico-montanos e áreas de tensão ecológica (transicionais) (figura 1). Entretanto, grande parte do município encontra-se antropizado, com vegetação secundária, áreas de pastagens e agricultura (Pinheiro 2004).

Foram realizadas cinco expedições ao campo entre junho de 2011 e abril de 2012. As coletas foram realizadas através de caminhadas aleatórias em fitofisionomias de caatinga, cerrado, campo rupestre, floresta estacional decídua, floresta ombrófila, e matas ciliar, de galeria e de grotão. Os indivíduos férteis foram coletados, herborizados e incorporados ao acervo do herbário ALCB. Foram analisados também materiais das coleções dos herbários ALCB, BHCB, CEPEC, HUEFS, HRB, HUFU e SPF (acrônimos conforme Thiers 2013), além de fotografias dos tipos.

A circunscrição taxonômica das tribos está de acordo com Funk et al. (2009). A terminologia específica da família segue Roque \& Bautista (2008).

\section{Resultados}

Asteraceae está representada em Jacobina por 15 tribos, 61 gêneros e 80 espécies e um híbrido (tabela 1).

\section{Chave para as espécies}

1. Ramos armados (presença de espinhos axilares); brácteas involucrais com apículos espinescentes, recurvados Dasyphyllum sp.

1. Ramos inermes (sem espinhos); brácteas involucrais não espinescentes

2. Ervas com folhas em roseta; capítulo solitário, escaposo, com três tipos de flores Chaptalia integerrima

2. Ervas, arbustos ou arvoretas com folhas opostas ou alternas; capitulescência não escaposa, capítulos com um a dois tipos de flores

3. Plantas com látex; todas as flores liguladas Sonchus oleraceus

3. Plantas sem látex; flores de outros tipos

4. Ramos alados

5. Capítulo radiado; pápus 2-aristado . Verbesina macrophylla

5. Capítulo discóide; pápus cerdoso ou ausente 
6. Capítulos sésseis, agrupados em espigas de glomérulos Pterocaulon alopecuroides

6. Capítulos pedunculados, agrupados em cimeiras corimbiformes

7. Pápus cerdoso Pluchea sagittalis

7. Pápus ausente Epaltes brasiliensis

4. Ramos não alados

8. Capítulos com quatro brácteas involucrais, decussadas Enydra radicans

8. Capítulos com quatro ou mais brácteas involucrais, imbricadas, subimbricadas, eximbricadas ou subiguais

9. Folhas e brácteas involucrais com pontuações glandulares alongadas, aromáticas

10. Lâmina foliar pinatífida; brácteas involucrais concrescidas

Tagetes minuta

10. Lâmina foliar inteira; brácteas involucrais livres

11. Capítulos discóides, invólucro 17-20 mm alt. Porophyllum ruderale

11. Capítulos disciformes, invólucro 2,5-4 mm alt. Flaveria trinervia

9. Folhas e brácteas involucrais sem pontuações glandulares aromáticas

12. Brácteas involucrais papiráceas, hialinas, amarelas Achyrocline satureioides

12. Brácteas involucrais cartáceas ou coriáceas, opacas, verdes ou castanhas

13. Cipsela com cerdas uncinadas (em forma de gancho) Acanthospermum hispidum

13. Cipsela lisa, sem tricomas uncinados

14. Invólucro com uma única série de brácteas

15. Capítulo disciforme; invólucro caliculado, brácteas involucrais conadas apenas na base; flores amarelas Erechtites hieraciifolius

15. Capítulo discóide; invólucro ecaliculado, brácteas involucrais conadas em toda a extensão; flores vermelhas ou róseas

16. Lâmina foliar fortemente dentada; invólucro 1-2 vezes mais longo que largo; flores maiores que o invólucro; corola vermelha Emilia fosbergii

16. Lâmina foliar lirado-lobada; invólucro 3-4 vezes mais longo que largo; flores tão longas quanto o invólucro; corola rosa Emilia sonchifolia

14. Invólucro com duas ou mais séries de brácteas

17. Capítulos homógamos com flores unissexuais (flores pistiladas ou estaminadas por aborto do gineceu)

18. Plantas monóicas (ramos da capitulescência com capítulos com flores pistiladas na base e com flores estaminas no ápice); lâmina foliar pinatissecta Ambrosia polystachya

18. Plantas dióicas; lâmina foliar inteira

19. Lâmina obovada, margem denteada Baccharis retusa

19. Lâmina ovado-lanceolada, margem inteira Baccharis trinervis

17. Capítulos homógamos com flores bissexuais ou capítulos heterógamos 20. Capítulo comprimido lateralmente, formado por três brácteas (uma maior foliácea e duas menores escariosas), com uma flor pistilada e uma estaminada Delilia biflora

20. Capítulo campanulado ou cilíndrico, formado por 4-muitas brácteas involucrais, com mais de duas flores

21. Capítulos discóides

22. Apêndice do conectivo da antera apiculado, estilete glabro

23. Subarbustos (caule não ramificado); flores com corola alva, pápus unisseriado Richterago discoidea

23. Árvores ou arbustos (caule ramificado); flores com corola creme, pápus bisseriado

24. Capítulos pedunculados, pedúnculos (4)8-20 mm compr. 
25. Arbustos, lâmina foliar elíptica .... Moquiniastrum floribundum

25. Árvores, lâmina foliar ovado-lanceolada

Moquiniastrum polymorphum

24. Capítulos sésseis a subsséseis pedúnculos 0-2 mm compr.

26. Arbustos 1-2 m alt.; lâmina foliar orbiculada a ovada; capitulescência maior ou do mesmo tamanho das folhas Moquiniastrum blanchetianum

26. Arbustos ou arvoretas 3-7 m alt.; lâmina foliar elíptica; capitulescência menor que as folhas

Moquiniastrum oligocephalum

22. Apêndice do conectivo da antera agudo ou obtuso, estilete piloso ou papiloso

27. Ramos do estilete com apêndices pilosos (pilosidade estendendo-se abaixo da bifurcação) ou papilosos, agudos 28.Ervas; caule fistuloso; lâmina foliar pinatilobada

Chresta pacourinoides

28. Subarbustos a arvoretas; caule meduloso; lâmina foliar inteira

29. Brácteas involucrais concrescidas na base; receptáculo profundamente alveolado envolendo a cipsela Albertinia brasiliensis

29. Brácteas involucrais livres; receptáculo nunca envolvendo a cipsela

30. Arbustos escandentes; capítulos sésseis agrupados em corimbos nas axilas das folhas ..... Piptocarpha leprosa

30. Subarbustos ou arbustos a arvoretas eretos; capítulos de outras formas

31. Capítulos solitários no ápice de ramos laterais ou terminais Centratherum punctatum

31. Capítulos agrupados em capitulescência

32. Pápus alaranjado Echinocoryne holosericea

32. Pápus alvo a creme

33. Capítulos envolvidos por brácteas externas folhosas; pápus unisseriado, cerdas dilatadas na base ... Elephantopus mollis

33. Capítulos não envolvidos por brácteas externas folhosas; pápus 2-5 séries, cerdas não dilatadas na base

34. Capitulescência formando umbelas congestas, glomérulos ou sincefalia (capítulos fundidos envolvidos por brácteas involucrais de segunda ordem)

35. Folhas congestas nos ramos (entrenós $<1,5 \mathrm{~mm}$ compr.), lâmina foliar 0,8-1,2 cm larg. Lychnophora blanchetii

35. Folhas laxas nos ramos (entrenós $>6 \mathrm{~mm}$ compr.), lâmina foliar 4-21 cm larg. 
36. Lâmina foliar revoluta, base auriculada; captitulescência racemosa; pápus bisseriado ... Paralychnophora reflexoauriculata

36. Lâmina foliar plana, base atenuada ou cuneada; capitulescência cimosa; pápus multisseriado

37. Capítulos 2-5 por glomérulo; cipsela 10-costada, glandular .... . Eremanthus capitatus

37. Capítulos numerosos (mais de 10) por glomérulo; cipsela prismática (angulosa), sem glândulas .... ........... Eremanthus capitatus $\times$ Paralychnophorareflexoauriculata

34. Capítulos dispostos em racemos, corimbos, cimeiras ou panículas.

38. Ramos hirsutos; receptáculo fimbriado ....... Blanchetia heterotricha

38. Ramos glabros ou com outros tipos de tricomas; receptáculo glabro

39. Capítulos ebracteados (sem bráctea na base)

40. Capítulos sésseis, dispostos em cimeiras escorpióides Cyrtocymura scorpioides

40. Capítulos pedunculados, dispostos em panículas 41. Lâmina foliar obovada ..... ... Vernonanthura brasiliana

41. Lâmina foliar elíptica ou estreito-elíptica

42. Lâmina foliar 9-14 cm compr.; invólucro 44-55 brácteas; 20-30 flores por capítulo Vernonanthura phosphorica

42. Lâmina foliar $3,5-7 \mathrm{~cm}$ compr.; invólucro 18-25 brácteas; 10-11 flores por capítulo .......... Vernonanthura subverticillata

39. Capítulos bracteados (presença de uma bráctea na base) 
43. Flores com corola alva

Lepidaploa hagei

43. Flores com corola lavanda a roxa

44. Lâmina foliar com glândulas na face abaxial; invólucro 7-10 mm compr. 45. Lâmina foliar 5-6,3 cm compr:; invólucro 7-8 $\mathrm{mm}$ compr. ... Lepidaploa muricata 45. Lâmina foliar $8,5-12 \mathrm{~cm}$ compr.; invólucro 9-10 mm compr. ....... salzmannii Lepidaploa

44. Lâmina foliar sem glândulas na face abaxial; invólucro 4-6 mm compr. 46. Brácteas involucrais de ápice acuminado, não mucronado, reflexo ...Lepidaploachalybaea 46. Brácteas involucrais de ápice arredondado, mucronado, reto ...... cotoneaster Lepidaploa

27. Ramos do estilete com apêndices papilosos, obtusos ou clavados 47. Invólucro com quatro brácteas; capítulo com quatro flores 48. Lâmina foliar triangular; capitulescência em corimbos Mikania micrantha

48.Lâmina foliar elíptica, cordiforme ou ovada, capitulescência em tirso ou panícula

49. Lâmina foliar elíptica, peninérvia; bráctea subinvolucral linear. Mikania elliptica

49. Lâmina foliar cordiforme ou ovada, quinquenérvia ou trinérvia; bráctea subinvolucral ovada ou lanceolada 50. Ramos densamente hirsutos; lâmina foliar cordiforme, hirsuta em ambas as faces, ápice longo-acuminado, base cordada

Mikania hirsutissima

50. Ramos glabros (exceto pedúnculos da capitulescência); lâmina foliar ovada, glabra em ambas as faces, ápice agudo, base cuneada

51. Bráctea subinvolucral ovada; brácteas involucrais com ápice arredondado, base sem proeminência evidente, margem plana . Mikania belemii

51. Bráctea subinvolucral espatulada; brácteas involucrais comápice agudo, base com proeminência evidente, margem levemente revoluta 
47. Número de brácteas involucrais diferente do número de flores

52. Pápus plumoso; corola com lobos densamente pubescentes

53. Lâmina foliar lanceolada a triangular, base truncada; flores 18-25 Trichogonia salviifolia

53. Lâmina foliar elíptica a estreito-elíptica, base atenuada; flores 30-40 Trichogonia campestris

52. Pápus cerdoso ou ausente; corola com lobos glabros, papilosos, com glândulas e/ou poucos tricomas

54. Folhas alternas, densamente espiraladas

55. Ramos do estilete pubescentes abaixo da bifurcação Stylotrichium corymbosum

55. Ramos do estilete glabros abaixo da bifurcação 56. Ramos, folhas e invólucro glabros, viscosos Bahianthus viscosus

56. Ramos, folhas e invólucro alvo-tomentosos, não viscosos Lasiolaena blanchetii

54. Folhas opostas, não espiraladas

57. Receptáculo paleáceo; pápus aristado ou coroniforme-laciniado

58. Folhas pecioladas, glutinosas, com ápice longo-acuminado, margem inteira e base aguda; pápus aristado... Acritopappus confertus

58. Folhas sésseis, não glutinosas, com ápice arredondado, margem denticulada e base cuneada; pápus coroniforme-laciniado Acritopappus micropappus

57. Receptáculo epaleáceo; pápus cerdoso

59. Capítulo com 4-5 flores

60. Folhas opostas, decussadas, glabras

Symphyopappus decussatus

60. Folhas alternas (ou às vezes opostas), dísticas, tomentosas ..... Bejaranoa semistriata

59. Capítulo com mais de 5 flores

61. Brácteas involucrais arredondadas no ápice

62. Invólucro cilíndrico; brácteas involucrais imbricadas; base do estilete pubescente ... Chromolaena morii

62. Invólucro campanulado, brácteas involucrais eximbricadas; base do estilete glabra ... Austroeupatorium inulifolium

61. Brácteas involucrais agudas ou acuminadas no ápice

63. Apêndice apical da antera retuso Diacranthera ulei

63. Apêndice apical da antera obtuso

64. Receptáculo cônico

Conocliniopsis prasiifolia

64. Receptáculo plano Koanophyllon conglobatum 
21. Capítulos disciformes ou radiados

65. Capítulos disciformes

66. Flores marginais com corola ligulada ..... Symphyotrichum squamatum

66. Flores marginais com corola filiforme ou tubulosa (rudimentares)

67. Folhas opostas; capítulos agrupados em corimbos congestos no ápice dos ramos Ichthyothere terminalis

67. Folhas alternas; capítulos agrupados em racemos ou panículas

68. Lâmina foliar (10-)15-20 mm larg.; capitulescência racemiforme, com menos de 20 capítulos ... Conyza primulifolia

68. Lâmina foliar 4-7 mm larg.; capitulescência paniculiforme, com mais de 30 capítulos ... Conyza sumatrensis

65. Capítulos radiados

69. Folhas alternas; pedúnculo fistuloso

70. Brácteas involucrais mais internas com ápice arredondado ou obtuso; corola amarela ... Tithonia diversifolia

70. Brácteas involucrais mais internas com ápice agudo; corola laranja

Tithonia rotundifolia

69. Folhas opostas; pedúnculo meduloso

71. Capítulos com todas as flores alvas ou as do raio alvas e as do disco amarelas

72. Pápus aristado

73. Lâmina foliar pinatissecta; cipsela fusiforme ... Bidens pilosa

73. Lâmina foliar inteira; cipsela prismática

Blainvillea acmella

72. Pápus plumoso ou ausente

74. Páleas planas; cipsela lisa e pilosa, pápus plumoso Tridax procumbens

74. Páleas filiformes; cipsela tuberculosa e glabra, pápus ausente Eclipta prostrata

71. Capítulos com todas as flores amarelas

75. Receptáculo cônico Acmella ciliata

75. Receptáculo plano ou côncavo

76. Arbustos escandentes; cipsela bacácea; pápus ausente .....

Tilesia baccata

76. Ervas ou arbustos eretos; cipsela de outros tipos; pápus presente

77. Brácteas involucrais cartáceas, estriadas; pápus de páleas livres Calea candolleana

77. Brácteas involucrais foliáceas, lisas; pápus aristado, coroniforme ou ausente

78. Lâmina foliar trilobada; flores do disco com tricomas nas lacínias Sphagneticola trilobata

78. Lâmina foliar inteira; flores do disco sem tricomas nas lacínias

79. Cipselas dimorfas (do raio com alas recortadas e do disco com três aristas)

79. Cipselas isomorfas Synedrella nodiflora

80. Plantas prostradas; flores do raio neutras ou estéreis Aspilia riedelii

80. Plantas eretas; flores do raio pistiladas e férteis

. Wedelia alagoensis 


\section{Discussão}

Assim como nos demais levantamentos florísticos realizados para a família em áreas da Cadeia do Espinhaço (Giulietti et al. 1987, Hind 1995, 2003; Zappi et al. 2003), as tribos mais representativas em Jacobina foram Vernonieae (21 espécies) e Eupatorieae (19) compondo juntas ca. $50 \%$ da flora local de Asteraceae. A maioria das tribos (10) apresentou 1-3 espécies cada, representando apenas $21 \%$ da riqueza de Asteraceae no município. Os gêneros com maior número de espécies foram Lepidaploa e Mikania (5 espécies cada), Moquiniastrum (4) e Vernonanthura (3). Quarenta e seis gêneros (74\%) estão representados no município por apenas uma espécie.

Dentre os táxons encontrados, Lepidaploa muricata é registrada como uma nova ocorrência para o Estado e sete espécies (Acritopappus micropappus, Dasyphyllum, Lasiolaena blanchetii, Lychnophora blanchetii, Mikania belemii, M. elliptica e Stylotrichium
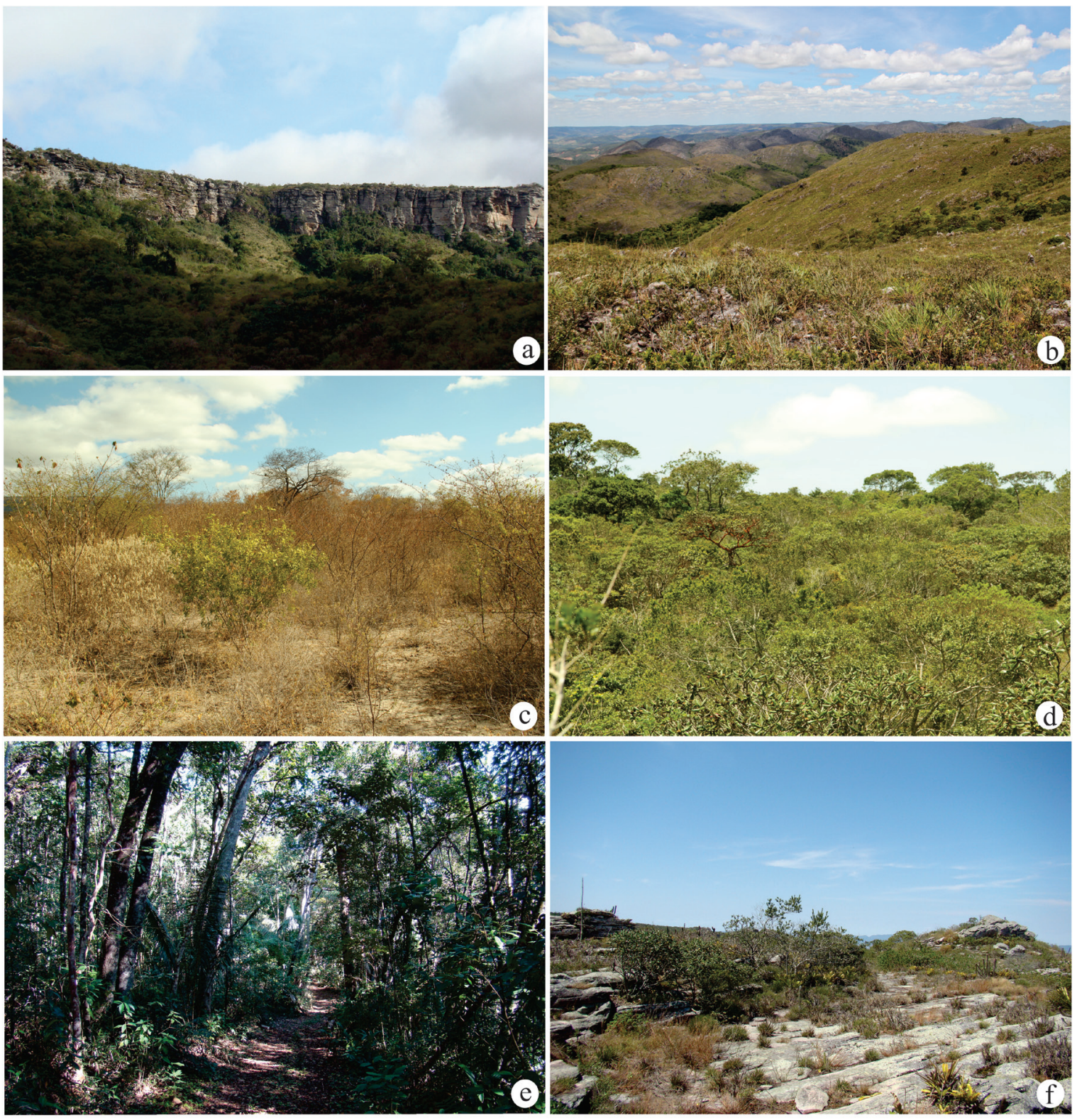

Figura 1. Serras e fitofisionomias presentes no município de Jacobina, Bahia, Brasil. a. Serra do Tombador. b. Parte da Serra da Jacobina. c. Caatinga arbustiva. d. Cerrado. e. Remanescente de Mata Atlantica. f. Campo rupestre.

Figure 1. Hills and vegetation types present in the municipality of Jacobina, Bahia, Brazil. a. The Tombador. b. Part of Serra de Jacobina. c. Shrub savanna. d. Cerrado. e. Remnant of Mata Atlantica. f. Rocky field. 
corymbosum) são consideradas endêmicas da Bahia. Albertinia brasiliensis, Aspilia riedelii, Chaptalia integerrima, Lepidaploa salzmannii, Tithonia diversifolia, T. rotundifolia e Wedelia alagoensis foram coletadas pela primeira vez em Jacobina, bem como Tridax procumbens, uma espécie amplamente distribuída em áreas antropizadas.
Dez espécies têm Jacobina como localidade-tipo (Acritopappus micropappus, Eremanthus capitatus, Moquiniastrum blanchetianum, Lasiolaena blanchetii, Lychnophora blanchetii, Mikania elliptica, Piptocarpha leprosa, Stylotrichium corymbosum, Symphyopappus decussatus e Vernonanthura subverticillata), tendo em vista que o município foi
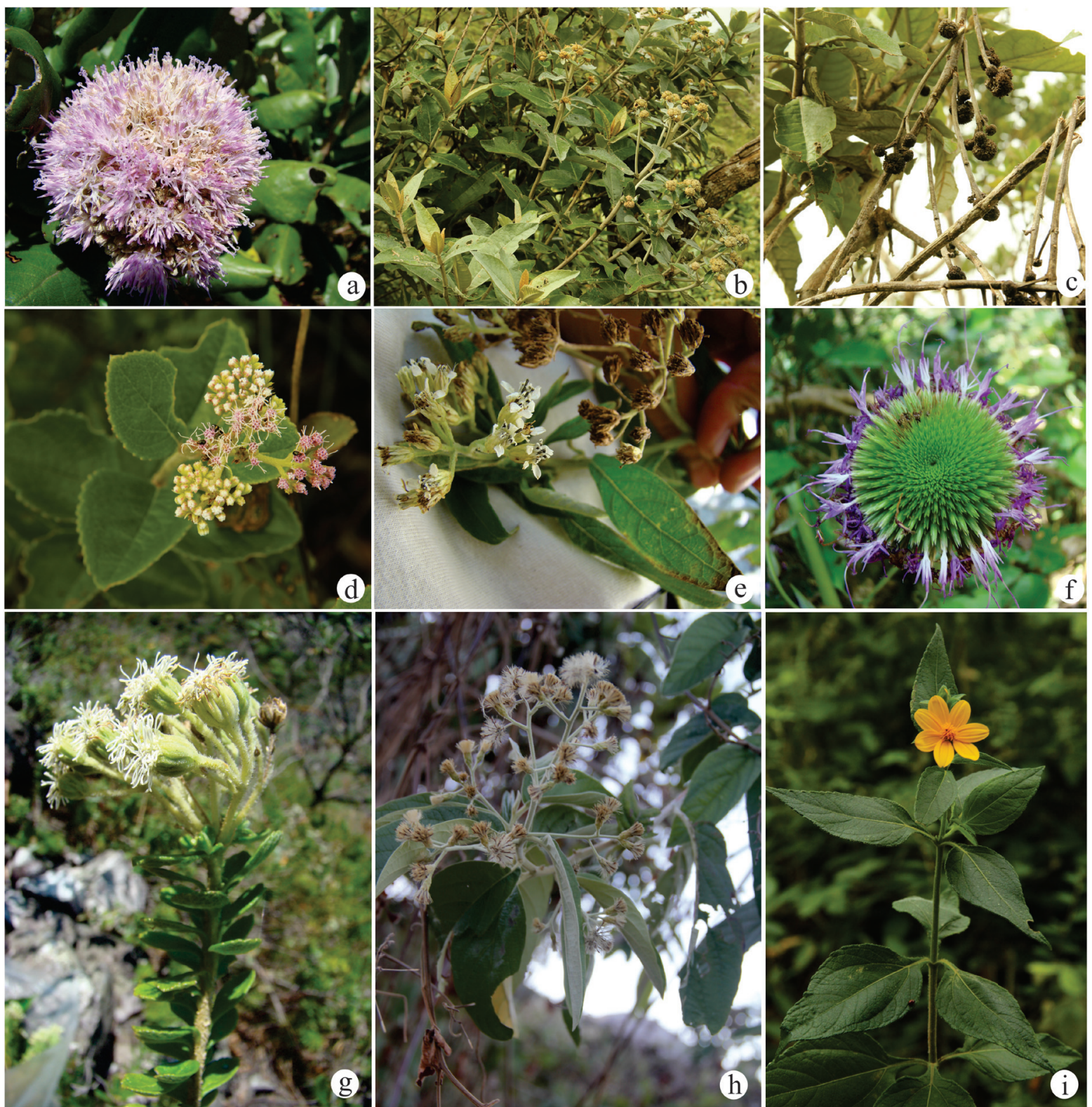

Figura 2.a. Paralychnophora reflexoauriculata (G.M. Barroso) MacLeish. b,c. Eremanthus capitatus (Spreng.) MacLeish $\times$ Paralychnophora reflexoauriculata (G.M. Barroso) MacLeish. d. Acritopappus micropappus (Baker) R.M. King \& H. Rob. e. Verbesina macrophylla (Cass.) S.F. Blake. f. Pithecoseris pacourinoides Mart. ex DC. g. Stylotrichium corymbosum (DC.) Mattf. h. Moquiniastrum polymorphum (Less.) Cabrera. i. Wedelia alagoensis Baker.

Figure 2.a. Paralychnophora reflexoauriculata (G.M. Barroso) MacLeish. b,c. Eremanthus capitatus (Spreng.) MacLeish $\times$ Paralychnophora reflexoauriculata (G.M. Barroso) MacLeish. d. Acritopappus micropappus (Baker) R.M. King \& H. Rob. e. Verbesina macrophylla (Cass.) S.F. Blake. f. Pithecoseris pacourinoides Mart. ex DC. g. Stylotrichium corymbosum (DC.) Mattf. h. Moquiniastrum polymorphum (Less.) Cabrera. i. Wedelia alagoensis Baker. 
Tabela 1. Lista das espécies de Asteraceae do município de Jacobina, Bahia, Brasil e voucher associado.

Table 1. List of species of Asteraceae of the municipality of Jacobina, Bahia, Brazil and associated voucher.

\begin{tabular}{|c|c|}
\hline Tribo/Espécie & Voucher \\
\hline \multicolumn{2}{|l|}{ Astereae } \\
\hline Baccharis retusa DC. & L.Moura et al. 180 \\
\hline Baccharis trinervis Pers. & L.Moura et al. 95 \\
\hline Conyza primulifolia (Lam.) Cuatrec. \& Lourteig & L.Moura et al. 69 \\
\hline Conyza sumatrensis (Retz.) E.Walker & L.Moura et al. 99 \\
\hline Symphyotrichum squamatum (Spreng.) G.L. Nesom & Giulietti et al. PCD 3389 \\
\hline \multicolumn{2}{|l|}{ Barnadesieae } \\
\hline Dasyphyllum sp. & J.L.Hage et al. 2291 \\
\hline \multicolumn{2}{|l|}{ Cichorieae } \\
\hline Sonchus oleraceus L. & N. Hind et al. PCD 3374 \\
\hline \multicolumn{2}{|l|}{ Coreopsideae } \\
\hline Bidens pilosa $\mathrm{L}$. & N. Hind et al. PCD 3341 \\
\hline \multicolumn{2}{|l|}{ Eupatorieae } \\
\hline Acritopappus confertus (Gardner) R.M.King \& H.Rob. & H.P.Bautista et al. 3074 \\
\hline Acritopappus micropappus (Baker) R.M. King \& H. Rob. & L.Moura et al. 179 \\
\hline Austroeupatorium inulifolium (Kunth) R.M.King \& H.Rob. & H.P.Bautista et al. 3055 \\
\hline Bahianthus viscosus (Spreng.) R.M. King \& H. Rob. & T.Ribeiro et al. 154 \\
\hline Bejaranoa semistriata (Sch. Bip. ex Baker) R.M. King \& H. Rob. & J.L.Hage et al. 2276 \\
\hline Chromolaena morii R.M. King \& H. Rob. & L.Moura et al. 100 \\
\hline Conocliniopsis prasiifolia (DC.) R.M. King \& H. Rob. & L.Moura et al. 74 \\
\hline Diacranthera ulei R.M. King \& H. Rob. & L.Moura et al. 96 \\
\hline Koanophyllon conglobatum (DC.) R.M. King \& H. Rob. & N. Hind et al. PCD 3441 \\
\hline Lasiolaena blanchetii (Sch. Bip. ex Baker) R.M. King \& H. Rob. & Blanchet 3698 \\
\hline Mikania belemii R.M. King \& H. Rob. & Giulietti et al. PCD 2669 \\
\hline Mikania elliptica DC. & L.Moura et al. 105 \\
\hline Mikania hirsutissima DC. & W. Fonseca 325 \\
\hline Mikania micrantha Kunth & R.Harley et al. PCD 3409 \\
\hline Mikania obovata DC. & R.Harley 16584 \\
\hline Stylotrichium corymbosum (DC.) Mattf. & L.Moura et al. 104 \\
\hline Symphyopappus decussatus Turcz. & Blanchet 3249 \\
\hline Trichogonia campestris Gardner & N. Hind et al. PCD 3342 \\
\hline Trichogonia salviifolia Gardner & L.Moura et al. 176 \\
\hline \multicolumn{2}{|l|}{ Gnaphalieae } \\
\hline Achyrocline satureioides (Lam.) DC. & L.Moura et al. 173 \\
\hline \multicolumn{2}{|l|}{ Gochnatieae } \\
\hline Moquiniastrum blanchetianum (DC.) Cabrera & L.Moura et al. 188 \\
\hline Moquiniastrum floribundum Cabrera & J.G.Jardim et al. 744 \\
\hline Moquiniastrum oligocephalum (Gardner) Cabrera & N. Hind et al. PCD 3336 \\
\hline Moquiniastrum polymorphum (Less.) Cabrera & L.Moura et al. 169 \\
\hline
\end{tabular}


Tabela 1 (continuação)

\begin{tabular}{|c|c|}
\hline Tribo/Espécie & Voucher \\
\hline Richterago discoidea (Less.) Kuntze & L.Moura et al. 186 \\
\hline Acmella ciliata (Kunth) Cass. & H.P.Bautista PCD 3458 \\
\hline Ambrosia polystachya DC. & N.Hind PCD 3382 \\
\hline Aspilia riedelii Baker & L.Moura et al. 187 \\
\hline Blainvillea acmella (L.) Philipson & R.Harley et al. PCD 3446 \\
\hline Delilia biflora (L.) Kuntze & N.Hind PCD 3438 \\
\hline Eclipta prostrata (L.) L. & N.Hind PCD 3381 \\
\hline Sphagneticola trilobata (L.) Pruski & M.Alves 28 \\
\hline Synedrella nodiflora (L.) Gaertn. & N.Hind PCD 3376 \\
\hline Tilesia baccata (L.) Pruski & L.Moura et al. 175 \\
\hline \multicolumn{2}{|l|}{ Tithonia diversifolia (Hemsl.) A. Gray } \\
\hline Tithonia rotundifolia (Mill.) S.F. Blake & M.Alves 30 \\
\hline Verbesina macrophylla (Cass.) S.F. Blake & L.Moura et al. 110 \\
\hline Wedelia alagoensis Baker & L.Moura et al. 167 \\
\hline \multicolumn{2}{|l|}{ Inuleae } \\
\hline Epaltes brasiliensis DC. & F.França et al. 3103 \\
\hline Pluchea sagittalis (Lam.) Cabrera & R.Harley et al. PCD 3410 \\
\hline Pterocaulon alopecuroides (Lam.) DC. & L.Moura et al. 84 \\
\hline \multicolumn{2}{|l|}{ Millerieae } \\
\hline Acanthospermum hispidum DC. & R.Harley et al. PCD 3448 \\
\hline Ichthyothere terminalis (Spreng.) S.F. Blake & F.R.Nonato 900 \\
\hline Tridax procumbens $\mathrm{L}$. & L.Moura et al. 71 \\
\hline \multicolumn{2}{|l|}{ Mutisieae } \\
\hline Chaptalia integerrima (Vell.) Burkart & L.Moura et al. 77 \\
\hline \multicolumn{2}{|l|}{ Neurolaeneae } \\
\hline Calea candolleana (Gardner) Baker & L.Moura et al. 185 \\
\hline Enydra radicans (Willd.) Lack & Giulietti et al. PCD 3387 \\
\hline \multicolumn{2}{|l|}{ Senecioneae } \\
\hline Emilia fosbergii Nicolson & L.Moura et al. 72 \\
\hline $\begin{array}{l}\text { Emilia sonchifolia (L.) DC. } \\
\text { Erechtites hieraciifolius (L.) Raf. ex DC. }\end{array}$ & $\begin{array}{l}\text { N.Hind PCD } 3379 \\
\text { R.P.Orlandi \& H.P.Bautista } 684\end{array}$ \\
\hline \multicolumn{2}{|l|}{ Tageteae } \\
\hline Flaveria trinervia (Spreng.) C. Mohr & N.Hind PCD 3373 \\
\hline Porophyllum ruderale (Jacq.) Cass. & L.Moura et al. 170 \\
\hline Tagetes minuta $\mathrm{L}$. & M.L. Guedes et al. 5085 \\
\hline \multicolumn{2}{|l|}{ Vernonieae } \\
\hline Albertinia brasiliensis Spreng. & L.Moura et al. 172 \\
\hline Blanchetia heterotricha DC. & L.Moura et al. 90 \\
\hline Centratherum punctatum Cass. & L.Moura et al. 111 \\
\hline Chresta pacourinoides (Mart. ex DC.) Siniscalchi \& Loeuille & L.Moura et al. 97 \\
\hline
\end{tabular}


Tabela 1 (continuação)

\begin{tabular}{ll}
\hline Tribo/Espécie & Voucher \\
\hline Cyrtocymura scorpioides (Lam.) H. Rob. & R.Orlandi 241 \\
Echinocoryne holosericea (Mart.) H. Rob. & W.Fonseca 305 \\
Elephantopus mollis Kunth & F.R.Nonato 866 \\
Eremanthus capitatus (Spreng.) MacLeish & L.Moura et al. 102 \\
Eremanthus capitatus (Spreng.) MacLeish $\times$ Paralychnophora reflexoauriculata & \\
(G.M. Barroso) MacLeish & L.Moura et al. 76 \\
Lepidaploa chalybaea (Mart. ex DC.) H. Rob. & N.G.Jesus et al. 1328 \\
Lepidaploa cotoneaster (Will. ex Spreng.) H. Rob. & L.Moura et al. 92 \\
Lepidaploa hagei (H. Rob.) H. Rob. & E.Melo 3932 \\
Lepidaploa muricata (DC.) H. Rob. & W.Fonseca 272 \\
Lepidaploa salzmannii (DC.) H. Rob. & L.Moura et al. 108 \\
Lychnophora blanchetii Sch. Bip. & J.S.Blanchet 3396 \\
Paralychnophora reflexoauriculata (G.M. Barroso) MacLeish & L.Moura et al. 101 \\
Piptocarpha leprosa (Less.) Baker & Blanchet, J.S. 3429 \\
Vernonanthura brasiliana (L.) H. Rob. & M.L.Guedes et al. 14857 \\
Vernonanthura phosphorica (Vell.) H.Rob. & L.Moura et al. 98 \\
Vernonanthura subverticillata (Sch. Bip. ex Baker) H. Rob. & L.Moura et al. 177 \\
\hline
\end{tabular}

rota de coleta de alguns naturalistas, principalmente J.S. Blanchet, que esteve na Bahia entre os anos de 1828 e 1856 e realizou coletas na Serra da Jacobina (Stafleu \& Cowan, 1976).

Foram registradas 24 espécies de Asteraceae que apresentam ampla distribuição geográfica (sensu Nakajima et al.2014) e crescem em ambientes urbanos ou antropizados. Destas, cinco são consideradas pelos mesmos autores como exóticas naturalizadas: Bidens pilosa, Tagetes minuta, Tilesia baccata, Tithonia diversifolia e Tithonia rotundifolia.

Este elevado número de espécies ruderais em Jacobina, quando comparado a outras áreas da Cadeia do Espinhaço, pode estar relacionado ao processo de antropização que diversas áreas do município têm sofrido, seja por impactos da agricultura e pastagens, como já apontado por Pinheiro (2004), ou por queimadas e exploração de rochas e minérios, como observado em campo.

Cabe destacar que certas espécies, mesmo não sendo ruderais, florescem quase o ano todo, como Acritopappus micropappus, Calea candolleana, Lepidaploa cotoneaster e Paralychnophora reflexoauriculata, enquanto outras florescem apenas em determinados meses do ano, a exemplo de Dasyphyllum sp., que floresce entre agosto e outubro (Saavedra 2010). Segundo ainda a autora, essa espécie é conhecida apenas em floresta estacional semidecídua no Estado da Bahia e caracteriza-se pelo formato globoso dos capítulos e pelas brácteas involucrais externas com apículos reclinados.

Algumas espécies são abundantes em várias fitofisionomias da região, entre elas, Eremanthus capitatus e Lepidaploa cotoneaster, que ocorrem em áreas de caatinga, floresta estacional semidecídua, remanescente de Mata Atlântica, cerrado e campo rupestre; e Calea candolleana, que ocorre tanto em campo rupestre, como em outros tipos vegetacionais do bioma Cerrado, mata ciliar, além de borda de floresta estacional semidecídua, beira de estrada e outras áreas antropizadas. Por outro lado, algumas espécies tiveram distribuição restrita a determinados ambientes, como Acritopappus micropappus, Paralychnophora reflexoauriculata, Richterago discoidea e Stylotrichium corymbosum, cujas ocorrências se deram apenas em áreas de afloramentos rochosos de altitudes mais elevadas (campo rupestre). Lychnophora blanchetii também só foi coletada em campo rupestre, porém em um único local (Toca de Areia), na Serra da Jacobina. Blanchetia heterotricha, por sua vez, foi encontrada apenas em caatinga; e Pithecoseris pacourinoides em área de transição caatinga-campo rupestre da Serra do Tombador.

Apesar de o município estar inserido no Bioma Caatinga (IBGE 2004), a maioria (79\%) das espécies 
de Asteraceae foi coletada em áreas de cerrado. Além disso, algumas espécies citadas por Nakajima et al. (2014) apenas para áreas de Mata Atlântica, foram também encontradas no município em outros tipos de ambientes: Diacranthera ulei (ecótono entre caatinga e cerrado), Moquiniastrum polymorphum (mata de encosta, em área de cerrado e área antropizada), Mikania belemii (mata ciliar, em uma área de cerrado) e Verbesina macrophylla (mata ciliar em área de campo rupestre e floresta estacional semidecídua).

Espécimes coletados em Jacobina e também analisados em alguns herbários visitados (ALCB, CEPEC e SPF) compartilharam características intermediárias entre Paralychnophora reflexoauriculata e Eremanthus capitatus (figura 2). A hipótese de hibridização entre esses dois táxons já foi discutida nos estudos moleculares realizados por Loeuille (2011).

\section{Agradecimentos}

Agradecemos ao PIBIC/FAPESB/UFBA, pela Bolsa de Iniciação Científica concedida à primeira Autora; aos Projetos PRONEM (PNE 164/2011) e REFLORA/CAPES/CNPq, pelo recurso concedido ao custeio das viagens de campo. Ao Silvano e Aloísio, pelas atividades como guia nas expedições de campo. Ao CNPq, pela bolsa PQ concedida à última autora.

\section{Literatura citada}

Almeida, G.S.S. 2008. Asteraceae Dumort. nos campos rupestres do Parque Estadual do Itacolomi, Minas Gerais, Brasil. Tese de Doutorado, Universidade Federal de Viçosa, Minas Gerais.

Anderberg, A.A., Baldwin, B.G., Bayer, R.G., Breitwieser, J., Jeffrey, C., Dillon, M.O., Idenas, P., Funk, V., Garcia-Jacas, N., Hind, D.J.N., Karis, P.O., Lack, H.W, Nesom, G., Nordenstam, B., Oberprieler, Ch., Panero, J.L., Puttock, C., Robinson, H., Stuessy, T.F., Susanna, A., Urtubey, E., Vogt, R., Ward, J. \& Watson, L.E. 2007. Compositae. In: J.W. Kadereit \& C. Jeffrey (eds.). The Families and Genera of Vascular Plants, 8. Springer, Berlin, pp. 61-588.

Funk, V.A. \& N. Roque 2011. The monotypic Andean genus Fulcaldea (Compositae, Barnadesioideae) gains a new species from northeastern Brazil. Taxon 60: 1095-1103.

Funk, V.A., Susanna, A., Stessy, T.F. \& Robinson, H. 2009. Classification of Compositae. In: Funk, V.A., Susanna, A., Stuessy, T. \& Bayer, R.J. (eds.). Systematics, Evolution, and Biogeography of Compositae. IAPT, Vienna, pp. 171-188.
Gentry, A.H. 1986. Species Richness and Floristic Composition of Choco Region Plant Communities. Caldasia, 15: 71-75.

Giulietti, A.M. \& Pirani, J.R. 1988. Patterns of geographic distribution of some plant species from the Espinhaço Range, Minas Gerais and Bahia, Brazil. In: Vanzolini, P.E. \& Heyer, W.R. (eds.). Proceeding of a workshop on Neotropical Distribution Patterns, Academia Brasileira de Ciências Rio de Janeiro, pp. 39-69.

Giulietti, A.M., Menezes, N.L., Pirani, J.R., Meguro, M. \& Wanderley, M.G.L. 1987. Flora da Serra do Cipó, Minas Gerais: caracterização e lista das espécies. Boletim de Botânica da Universidade de São Paulo 9: $1-151$.

Hind, D.J.N. 1995. Compositae. In: B.L. Stannard (ed.). Flora of Pico das Almas - Chapada Diamantina, Bahia, Brazil. Royal Botanic Gardens, Kew, pp. 175-278.

Hind, D.J.N. 2003. Flora of Grão-Mogol, Minas Gerais: Compositae (Asteraceae). Boletim de Botânica da Universidade de São Paulo 21: 179-234.

IBGE. 2004. Mapas temáticos: Biomas. Disponível em http://mapas.ibge.gov.br/tematicos (acesso em 02-XII-2013).

Kruckeberger, A.R. \& Rabinowitz, D. 1985. Biological Aspects of Endemism in Higher Plants. Annual Review Ecology and Systematics, 16: 447-479.

Loeuille, B. 2011. Towards a phylogenetic classification of Lychnophorinae (Asteraceae: Vernonieae). Universidade de São Paulo, São Paulo.

Nakajima, J.N., Loeuille, B., Heiden, G., Dematteis, M., Hattori, E.K.O., Magenta, M., Ritter, M.R., Mondin, C.A., Roque, N., Ferreira, S.C., Teles, A.M., Borges, R.A.X., Monge, M., Bringel Jr., J.B.A., Oliveira, C.T., Soares, P.N., Almeida, G., Schneider, A., Sancho, G., Saavedra, M.M., Liro, R.M., Souza-Buturi, F.O., Pereira, A.C.M., Moraes, M.D., Silva, G.A.R., Medeiros, J.D, Siniscalchi, C.M., Lorencini, T.S. 2014. Asteraceae. In: Lista de Espécies da Flora do Brasil. Jardim Botânico do Rio de Janeiro. Disponível em http://floradobrasil.jbrj.gov.br/jabot/floradobrasil/ FB55 (acesso em 16-III-2014).

Panero, J.L. \& Funk, V.A. 2008. The value of sampling anomalous taxa in phylogenetic studies: Major clades of the Asteraceae revealed. Molecular Phylogenetics and Evolution 47: 757-782.

Pinheiro, C.F. 2004. Avaliação geoambiental do município de Jacobina-BA através das técnicas de geoprocessamento: um suporte ao ordenamento territorial. Dissertação de Mestrado. Universidade Federal da Bahia.

Quaresma, A.S., Nakajima, J.N. \& Roque, N. 2013. Stevia grazielae (Asteraceae: Eupatorieae: Ageratinae): a new species from the Cadeia do Espinhaço, Minas Gerais, Brazil. Kew Bulletin 68: 647-650.

Rapini, A., Mello-Silva, R., Kawasaki, M.L. 2002. Biodiversity and Conservation 11: 1733-1746. 
Roque, N. 2001. Notas sobre a fenologia de Wunderlichia mirabilis Riedel ex Baker (Compositae, Mutisieae) na Serra do Cipó, Minas Gerais, Brasil. Sitientibus. Série Ciências Biológicas 1: 108-111.

Roque, N. 2005. A new species of Chaptalia (Compositae, Mutisieae) from Minas Gerais, Brasil. Kew Bulletin 60: 133-135.

Roque, N. \& Nakajima, J.N. 2001. Two new species of Richterago Kuntze (Asteraceae, Mutisieae) from Minas Gerais and Goiás, Brazil. Kew Bulletin 56: 697-703.

Roque, N. \& Bautista, H.P. 2007. Redescoberta de Scherya bahiensis R.M.King \& H. Rob. (Compositae) na Chapada Diamantina, Bahia, Brasil. Boletim de Botânica 25: 149-151.

Roque, N. \& Bautista, H.P. 2008. Asteraceae: Caracterização e Morfologia Floral. EDUFBA, Salvador.

Roque, N. \& Santana, F.A. 2014. A New Species for a Monotypic Genus: Anteremanthus (Asteraceae: Vernonieae). Systematic Botany, v.39, pp. 656-661.
Saavedra, M.M. 2010. Sistemática de Dasyphyllum (Asteraceae). Tese de Doutorado, Instituto de Pesquisas Jardim Botânico do Rio de Janeiro/Escola Nacional de Botânica Tropical, Rio de Janeiro.

SEI - Superintendência de Estudos Econômicos e Sociais da Bahia. 2014. Disponível em www.sei.ba.gov.br. (acesso em 18-III-2014).

Stafleu, F.A. \& Cowan, R.S. 1976. Taxonomic Literature Bohn, Scheltema \& Holkema, Utrecht, v.1, pp. 228. Disponível em http:/www.biodiversitylibrary.org/ item/103414\#page/11/mode/1up (acesso em 17-III-2014).

Thiers, B. 2013. Index Herbariorum: A Global Directory of Public Herbaria and Associated Staff. New York Botanical Garden's Virtual Herbarium. http://sweetgum. nybg.org/ih/ (acesso em 25.06.2013).

Zappi, D.C., Lucas, E., Stannard, B.L., Lughadha, E.N., Pirani, J.R., Queiroz, L.P., Atkins, S., Hind, D.J.N., Giulietti, A.M., Harley, R.M. \& Carvalho, A.M. 2003. Lista das plantas vasculares de Catolés, Chapada Diamantina, Bahia, Brasil. Boletim de Botânica da Universidade de São Paulo 21: 251-400. 
